\title{
Balance between foundations and creativity: features of Korean mathematics education
}

\author{
Introduction to this issue
}

\author{
Oh Nam Kwon $\cdot$ Sung Je Cho
}

Published online: 28 April 2012

(c) FIZ Karlsruhe 2012

We are very pleased to write this introductory paper to the special issue of ZDM that provides readers with a glimpse of mathematics education in Korea. In July 2012 (7th-15th), the 12th International Congress on Mathematical Education (ICME-12) takes place at COEX in the center of Seoul, Korea. The ICME is the most important congress in the mathematics education community. It is held once every 4 years under the auspices of the International Commission of Mathematical Instruction (ICMI). The impetus for having this special issue during ICME-12 arose from the scarcity of literature on Korean mathematics education despite Korean students' high achievement on international comparison studies.

Korean students have consistently performed well in recent international assessments of mathematics achievement such as the Trends in International Mathematics and Science Study (TIMSS), the OECD Program for International Student Assessment (PISA), and the International Mathematics Olympiad. In addition, a recent study titled Mathematics Teaching in the 21st Century (MT21) compared prospective teachers' knowledge and beliefs about teaching and learning in six participant countries, reporting that Korean prospective secondary mathematics teachers were better prepared than those in other countries (Schmidt et al., 2007; Schmidt, Blömeke, Tatto, 2011).

Despite such outstanding performances of Korean students and prospective teachers, very little literature is available on factors that contribute toward it. In addition

O. N. Kwon $(\varangle) \cdot$ S. J. Cho

Department of Mathematics Education, College of Education,

Seoul National University, Gwanak-ro 1, Gwanak-gu, Seoul

151-748, Korea

e-mail: onkwon@snu.ac.kr

S. J. Cho

e-mail: sunghcho@snu.ac.kr relatively little is also written about mathematics education in Korea. Many scholars, particularly in the West, are curious about Korea's excellence in teacher quality and student achievement (e.g. Akiba, LeTendre, \& Scribner, 2007; Kang \& Hong, 2008). There are, however, a relatively small set of systematic studies that examine various aspects of Korean mathematics education substantively and carefully (Kwon, Park, \& Park, 2011).

Further, some studies on Asian education have even mistakenly assumed that mathematics education in Korea is almost the same as that in other East Asian countries (e.g., Leung, 2011). Considering teaching and learning as cultural practices (e.g., Alexander, 2000; Fernandez \& Yoshida, 2004; Ma, 1999; Stigler \& Hiebert, 1999), this could mislead readers to ignore the uniqueness of mathematics education in Korea. As a historical-cultural construct, educational practice of mathematics is situated in a specific cultural context of South Korean society, where there are a range of unique cognitive and normative assumptions around the functions and purposes of education, the kinds of knowledge pursued in school and society, the roles taken by teachers and students.

Thus, this special issue not only overviews major aspects of Korean mathematics education, it also addresses the historical and cultural foundations of Korean mathematics education in order to foster an understanding of its practices.

This issue, a thematic collection of studies, consists of nine papers that present and discuss emerging issues and challenges of Korean mathematics education with respect to various aspects of mathematics education such as curriculum, teaching practices, student learning, textbooks, assessment, and teacher education. It makes an important contribution by Korean mathematics educators to the international community. 
The first paper by Hee Chan Lew et al., entitled New challenges in the 2011 revised middle school curriculum of Korea: Mathematical process and mathematical attitude, provides detailed information on the main content of the key changes in the five domains such as 'number and operations,' 'letters and expressions,' 'functions,' 'probability and statistics,' and 'geometry.' They stress nurturing mathematical creativity and personality through the development of mathematical thinking, as well as character-building as a mathematical learner, via the changes in the school curriculum of Korea.

The paper by Kyungmee Park, entitled Characteristics of mathematics lessons in Korea: Two faces-conventional lesson and innovative lesson, reports two different kinds of teaching in the Korean classroom. She analyzed conventional lessons and innovative lessons from the perspective of the theory of variation and Lakatos' proofs and refutations, respectively. She claimed that mathematics classrooms in Korea are influenced by Chinese Heritage Culture. The author concluded that the two faces of mathematics lessons look very different, but they may flow from the same heart of an East Asian pragmatism.

The third and fourth papers focus on teaching practices in innovative classrooms. JeongSuk Pang explores culturally specific values and expectations of mathematics instruction in Korean contexts by tracing one teacher's change and struggles in teaching mathematics in reformoriented ways. Specifically, the author attempts to address what has changed and not changed in the teacher's classroom practice. The author identified 'focusing on important mathematics content' as culturally specific characteristics and values which influence effective mathematics instruction in Korea. Such characteristics are universal characteristics identified across different cultures (e.g., National Council of Teacher of Mathematics, 2000). Further, with regards to the unchanged practices, possible factors were also inferred. Some of these factors were the characteristics of Korean mathematics textbooks, teacher beliefs of which things influence effective mathematics instruction, and different nuances of student-centeredness across various education systems.

The fourth paper by Dongwon Kim and Mi-Kyung Ju, entitled A changing trajectory of proof learning in geometry inquiry classroom, investigates a geometry class based on inquiry-oriented approach and provides a detailed description of how the participants of the class-the teacher as well as the students-had changed over the class participation. They identified three stages of the transformation and provided a description how the students' practice of mathematical proofs had been transformed in the inquiry-oriented geometry class over the three stages.

The fifth and sixth papers attempt to compare textbooks from Korea and the US from the perspective of cognitive complexity and non-textual elements. The fifth paper by Ji-Won Son, entitled A cross-national comparison of reform curricula in Korea and the US in terms of cognitive complexity: The case of fraction addition and subtraction, examined the depth and breadth of the cognitive complexity of mathematical tasks presented in three sets of curriculum materials: mathematics textbooks from the 7th mathematics curriculum (KM1), those from the amended 7th mathematics curriculum (KM2), and those from one US reform curriculum, Everyday Mathematics (EM) in order to characterize current reform efforts in Korea. Findings from her study revealed that the KM2 provided better learning opportunities for students to learn fraction addition and subtraction than the KM1 in terms of the breadth and depth of cognitive complexity. Also, her depth of knowledge framework revealed greater depth in the types of problems offered in the KM2. This study showed that EM provided more cognitively balanced and challenging learning opportunities on fraction addition and subtraction that the KM2.

On the other hand, Rae Young Kim's paper examined three textbooks in Korea and three textbooks in the US focusing on non-textual elements on the topics of angle, slope, and prime factorization. Using a conceptual framework including accuracy, connectivity, contextuality, and conciseness, the main finding from her study was that connectivity and conciseness of non-textual elements were significantly different across topics, especially between angle and prime factorization, while accuracy and contextuality were not significantly different across topics. Also, while the Korean textbooks did not differ in terms of accuracy, connectivity and conciseness, the author revealed that there were significant variations among the selected US textbooks in terms of all the aspects but accuracy. Finally, this result implies different opportunities to learn through non-textual elements.

The seventh paper by Kyong Mi Choi, et al., entitled $A$ Comparative Investigation of Presence of Psychological Conditions in High Achieving Eighth Graders from TIMSS 2007 Mathematics, focuses on high achieving students (top $5 \%$ ) in TIMSS 2007 mathematics. The authors attempted to answer two questions: (1) if high achieving students possess three elements of Kruteskii's psychological conditions in comparison to their non-high achieving peers and (2) how Korean high achievers show these psychological conditions differently from other high achievers in the TIMSS 2007 mathematics test. After analyzing 44,567 students across ten high performing countries in TIMSS 2007, they concluded that although high achievers tended to express higher confidence in doing mathematics than non-high achievers, variations exist depending on countries. Specifically, high achievers in Asian countries expressed less confidence than those from other countries. 
In particular, Korean high achievers were found to express the least confidence among high achievers from Asia.

The eighth paper by Jung Sook Park and Jeehyun Park explores the changes in assessment at middle school level for the new national curriculum due for implementation in 2013 and attempts to provide future directions for assessment by analyzing national-level mathematics achievement test as well as classroom-level assessment.

The last paper by Oh Nam Kwon and Mi-Kyung Ju, entitled Standard for professionalization of mathematics teacher: Policy, curricula, and national employment test in Korea examines the curricular structure of the mathematics teacher preparation program and the coverage of content in the teacher employment tests in order to investigate the expectation for teacher professionalization in terms of teacher knowledge. Their study was set in the background of (a) the TIMSS and PISA studies which reveal a much higher performance by Korean students, (b) the MT 21 study which reveals a higher level of preparation reached in comparison to other countries and (c) more recent studies (e.g. Kim et al., 2011; Kwon, 2004) showing that Korean teacher education curricula included a greater emphasis on content knowledge relative to that of the US. Kwon and Ju's findings support those of (b) and (c). They share the view that a part of the superior performance of Korean students in TIMSS and PISA may be attributed to the higher level of teacher preparation. They have supported the findings of (c) by showing that Korean teacher education curricula and employment tests emphasized not only mathematical content but also pedagogical knowledge, both general and more importantly subject centered pedagogical knowledge. This trend has been strengthened further through the teacher education reforms implemented since 2009.

In the last 70 years, Korea has progressed from being one of the poorest countries in the world to the top performing country on international comparison tests with more than $80 \%$ of youth now attending some form of higher education and a rapidly expanding economy. The world frequently cites Korea as its model for education excellence. Often much of this evidence rests on its performance in mathematics. Yet, for the Korean society, this very success comes as a mixed blessing.

The very success of mathematics education is a result of a singular focus of schools on academic success. This singular focus, while a primary reason for academic success on tests, also means that some creativity, innovative skills and collective learning skills are foregone in schools. The society recognizes that these skills are keys in a knowledge based society. Building such skills into a mathematics curriculum and pedagogy is key and the focus of mathematics educators and research into the future.

Thus, while Korea has certainly achieved considerable success in education and has found ways of teaching mathematics successfully in its schools, it still faces challenges. This dedicated issue demonstrates that the technical challenges are engaged with enthusiasm and professionalism. Koreans love challenge and apply themselves to overcoming challenges. But with success comes further challenges and the price of mathematics success is the clear need for further educational reform-the challenge of our future. As editors of this special issue we would like to see the many educational reform issues addressed by this set of papers in future research and development on Korea mathematics education.

Acknowledgments We would like to thank all the contributors who worked hard to follow the timelines of preparation and publication. Also, we would like to thank twenty-seven reviewers who played a significant role through many rounds of review to help authors improve their papers. Specifically, we are very grateful to international reviewers, Shuhua An, Jinfa Cai, Berinderjeet Kaur, Karen Keene, Fredrick Leung, Sqli Li, Chris Rasmussen, and K. Subramaniam. Our special thanks go to Gabriele Kaiser, the journal editor-in-chief of ZDM, for her encouraging and consistent support and patience. Finally, we would like to appreciate Lyn Ilon at Seoul National University for her language editing on our manuscript.

\section{References}

Akiba, M., LeTendre, G. K., \& Scribner, J. P. (2007). Teacher quality, opportunity gap, and national achievement in 46 countries. Educational Researcher, 36(7), 369-387.

Alexander, R. J. (2000). Culture and pedagogy: International comparisons in primary education. Malden, MA: Blackwell Publishing.

Fernandez, C., \& Yoshida, M. (2004). Lesson study: A Japanese approach to improving mathematics teaching and learning. Mahwah, NJ: Lawrence Erlbaum Associates.

Kang, N.-H., \& Hong, M. (2008). Achieving excellence in teacher workforce and equity in learning opportunities in South Korea. Educational Researcher, 37(4), 200-207.

Kim, R. Y., Ham, S.-H., \& Paine, L. W. (2011). Knowledge expectations in mathematics teacher preparation programs in Korea and the United States: Towards international dialogue. Journal of Teacher Education, 62(1), 48-61.

Kwon, O. N. (2004). Mathematics teacher education in Korea. Paper presented at the International Congress on Mathematical Education (ICME-10), Copenhagen, Denmark.

Kwon, O. N., Park, J. H., \& Park, J. S. (2011). Model lessons of mathematical practice focus on creativity and character education curriculum. Journal of the Korea Society of Mathematical Education Series A: The Mathematical Education, 50(4), 403-428.

Leung, F. (2011). Mathematics education in Hong Kong and Korea: Similarities and differences. In O.N. Kwon (Ed.), Current issues $\&$ future directions of mathematics education in Asia, Proceeding of symposium on mathematics education in Asia. Seoul: Seoul National University.

Ma, L. (1999). Knowing and teaching elementary mathematics: Teachers' understanding of fundamental mathematics in China and the United States. Mahwah, NJ: Lawrence Erlbaum Associates.

National Council of Teacher of Mathematics. (2000). Principles and standards for school mathematics. Reston, VA: National Council of Teacher of Mathematics. 
Schmidt, W. H., Blömeke, S., Tatto, M. T., Hsieh, F.-J., et al. (2011). Teacher education matters. a study of middle school mathematics teacher preparation in six countries. New York: Teachers College Press.

Schmidt, W. H., Tatto, M. T., Bankov, K., Blömeke, S., Cedillo, T., Cogan, L., et al. (2007). The preparation gap: Teacher education for middle school mathematics in six countries (MT21 report).. East Lansing, MI: Center for Research in Mathematics and Science Education, Michigan State University.

Stigler, J. W., \& Hiebert, J. (1999). The teaching gap: Best ideas from the world's teachers for improving education in the classroom. New York: Free Press. 